\title{
CHANGE MANAGEMENT AND DIGITAL AGE TRAINING
}

\section{Venelin Terziev ${ }^{1}$, Robert Dimitrovski ${ }^{2}$, Liljana Pushova ${ }^{3}$, Marin Georgiev ${ }^{4}$, Denis Solovev ${ }^{5}$}

${ }^{1}$ Full Member of the Russian Academy of Natural History, Professor, Eng., D.Sc. (National Security), D.Sc. (Economics), D.Sc. (Social Activities), Ph.D., Russian Academy of Natural History, Moscow, Russia, Vasil Levski National Military University, Veliko Tarnovo, Bulgaria University of Rousse, Rousse, Bulgaria, terziev@skmat.com

${ }^{2}$ Full professor, Ph.D., Institute of Knowledge Managament, Skopje, Republic of N. Macedonia, dimitrovski.r@gmail.com

${ }^{3}$ Teaching assistant, Faculty of Economics, MIT Univeristy, Skopje, Republic of N. Macedonia, liljanapusova@yahoo.com

${ }^{4}$ Ph.D., National Military University, Veliko Tarnovo, Bulgaria, clementon@abv.bg

${ }^{5}$ Associate Professor, Ph.D., Far Eastern Federal University (FEFU), Vladivostok, Russian

Federation, solovev.db@dvfu.ru

\begin{abstract}
Change management is a scientific area that treats all aspects of changes in the global society and contemporary economy. Nowadays, changes have become more universal and essential social and organizational phenomenon. The modern society has brought the imperative of constant change. In order to maintain efficiency, profit and sustainability, all organizations must be proactive, instead of reactive in regards of implementation of changes. It has been discussed many times that today's changes have become more broad, rapid, unpredictable and severe - however, changes are inevitable part of the life cycles of all organizations. Most institutions have no awareness of or strategic approach to change management at all; they either talk about a change too much (or not at all), make the change, and hope for the best - treating a change as an event instead of an ongoing, everlasting process. The main problem is that changes are not thought about systemically or holistically, as they should be treated. Technology and changes have a huge impact on every aspect of life, with no exception to education. Educational institutions undoubtedly represent significant part of the whole process. Educational institutions are facing big cultural, demographic and especially technological shifts. Today, teachers are challenged with new ways of teaching in the digital age, incorporating technology effectively in the educational settings. In this paper the authors will discuss the matter of change management, digital age teaching and its impact of the educational practices and experiences. In this context, the method used is content analysis of relevant documents, as well as results of previous theoretical and empirical studies of many scientists and researchers in this particular field. The conclusions which have been reached represent a relevant starting point for future action in the framework of educational activities, policies and prospects.
\end{abstract}

Keywords: change management, teaching processes, digital age, transformation, challenges. 


\section{INTRODUCTION}

Changes which happen constantly in the contemporary economy inevitably lead to social, commer-cial, political, economic and cultural transformation of the organizations. When we talk about a specific organizational structure and companies as a coherent system, then it is certain that "the traditional companies have to change their business operations and direct them towards new technologies in order to remain competitive in the new conditions. It is evident that the success of the economy of the twen-ty-first century is based on three main parameters: information, ideas and intelligence" (Cvetković, Kotlica, 2007, p. 85).

There are two major kinds of organizational changes - changes imposed by circumstances (internal and external surroundings) and change that is planned and adopted to encourage growth or improve-ment within the companies (proactive changes). These changes apply to both individuals and large-scale enterprise organizations (Dimitrovski, 2012, p.32). Change management systems and models are designed to help businesses plan and implement the change (proactive approach) instead of react to it (reactive approach).

In the literature it is discussed about numerous classifications and typologies of change, based on different criteria, such as: global, regional, local, personal, organizational, radical, progressive, etc. Change means "process, but the result (of a single) process; changes are the source of the crisis, but also a response to the crisis; change is a challenge, but also a response to the challenge" (Alibabić, 2010, p. 104).

The philosophies discussed in today's change management policies and practices are structured to plan (rather than to react) to the challenge of organizational changes. This represents a growing indus-try with thousands of books and many theoretical management frameworks and models that address both the necessity and the problems involved in managing, planning and implementation of the organ-izational change.

The concept of change management dates back to the early to mid-1900s. Kurt Lewin's 3-step model for change ("Unfreeze - Change - Refreeze") (Hussain et all, 2018a) was developed in the 1950s; Everett Rogers' book Diffusion of Innovations was published in 1962, and Bridges' Transition Model was developed in 1979. However, it wasn't until the 1990s that change management became well known in the business environment, and formal organizational processes became available in the 2000s.

Change management is most often associated with the work of organizations and institutions that are changing under the constant influence of the environment (internal and external), or by the action the socalled innovative organizations and institutions (learning institution, lifelong learning concept).

Change management is a very complex process and it necessarily requires quality and software- oriented enterprises, because in the beginning there is, by default, some resistance to change by the majority of those to whom the changes are directed.

Permanent and significant changes are also present in the programs or systems of education and learning in the educational institutions. Innovative changes in the educational system are the main fac-tor for development and harmonization of modern social trends. The educational system/ institutions must effectively respond to the changes and the growing needs of the business sector, which is a direct consumer of the products of the educational system (skilled and knowledgeable workers).

Practice has shown that in the changing social and working environment only those organizations and institutions that can adapt to these changes can exist and work with significant success, ie. only those organizations which possess the skills and knowledge of change management can be competitive in the standards set by the modern, fast-moving, flexible economy. When it comes to the educational system, particularly to teachers and trainers (educators) from which the transfer of new knowledge and skills to younger generations who will take over the burden of social management, development and living depends, change management and implementation of new practices is even more significant (Dimitrovski, 2012, p.128).

\section{CHANGE MANAGEMENT AND DIGITAL AGE TRAINING}

\section{Steps for effective change management process}

All organizations are constantly experiencing change. Whether caused by new technology imple-mentations, process updates, compliance initiatives, reorganization, or customer service improvements, change is constant and necessary for growth, sustainability and profitability. A consistent change management process and program will aid in minimizing the negative impact changes have on the or-ganization and the staff.

Below we tried to summarize the essential steps to ensure that the change initiative is successfully 
implemented within the organization.

\section{- Identification of the aspects which will be improved}

Since most change occurs to improve a process, a product, or an outcome, it is critical to identify the focus and to clarify goals. This also involves identifying the resources and individuals that will facilitate the process and lead the endeavor. Most change systems acknowledge that knowing what to improve creates a solid foundation for clarity, ease, and successful implementation.

\section{- Presentation of a solid business case to all stakeholders}

There are several layers of stakeholders that include upper management who both direct and finance the endeavor, champions of the process, and those who are directly charged with instituting the new normal. All have different expectations and experiences and there must be a high level of "buy-in" from across the spectrum. The process of onboarding the different constituents varies with each change framework, but all provide plans that call for the time, patience, and communication.

\section{- Planning of the change which is to be implemented}

This is the "roadmap" that identifies the beginning, the route to be taken, and the destination. Through this step the organizations will also integrate resources to be leveraged, the scope or objective, and costs into the plan. A critical element of planning is providing a multi-step process rather than sudden, unplanned changes. This involves outlining the project with clear steps with measurable targets, incentives, measurements, and analysis. For example, a well-planed and controlled change management process for IT services will dramatically reduce the impact of IT infrastructure changes on the business. There is also a universal caution to practice patience throughout this process and avoid shortcuts.

\section{- Provision of resources and use of significant data for evaluation}

As part of the planning process, resource identification and funding are crucial elements. These can include infrastructure, equipment, and software systems. Organizations shall also consider the tools needed for reeducation, retraining, and rethinking priorities and practices. Many models identify data gathering and analysis as an underutilized element. The clarity of clear reporting on progress allows for better communication, proper and timely distribution of incentives, and measuring successes and milestones.

\section{- Communication}

This is the basic element that runs through the entire practice of change management. Identifying, planning, onboarding, and executing a good change management plan is dependent on good commu-nication. There are psychological and sociological realities inherent in group cultures. Those already involved have established skill sets, knowledge, and experiences. But they also have pecking orders, territory, and corporate customs that need to be addressed. Providing clear and open lines of commu-nication throughout the process is a critical element in all change modalities. The methods advocate transparency and two-way communication structures that provide avenues to vent frustrations, applaud what is working, and seamlessly change what doesn't work.

\section{- Monitoring and managing resistance, dependencies and budgeting risks}

Resistance is a very normal part of change management, but it can threaten the success of a project. Most resistance occurs due to a fear of the unknown. It also occurs because there is a fair amount of risk associated with change - the risk of impacting dependencies, return on investment risks, and risks associated with allocating budget to something new. Anticipating and preparing for resistance by arm-ing leadership with tools to manage it will aid in a smooth change lifecycle.

- Celebration of the success of the change

Recognizing milestone achievements is an essential part of any project. When managing a change through its lifecycle, it's important to recognize the success of teams and individuals involved. This will help in the adoption of both change management process as well as adoption of the change itself.

- Review, revision and continuous improvement

As much as change is difficult and even painful, it is also an ongoing process. Even change man-agement strategies are commonly adjusted throughout a project. Like communication, this should be significantly noticed through all steps to identify and remove roadblocks. And, like the need for re-sources and data, this process is only as good as the commitment to measurement and analysis. 


\section{Education - challenges and perspectives}

From the end of the 20th and early 21st century there has been noted a large increase of the interest in knowledge (education), which is now considered the only guarantee to achieve competitive ad-vantage of the organization (whether it is a for profit or non- profit organizations). The survival of the organization depends on its ability to adapt to the dynamics of the adequate environment in which it operates. This requires that the organization possesses, investigates and analyzes various information from the environment, but the job requires an approach that can be implemented only under the condi-tion that the organization has competent, skilled and educated people/workers. Such personnel are able to analyze the process and use the information from the environment and to harmonize their activities in line with what the market demands and requests. Creating and transferring knowledge within the organization becomes "a decisive factor in achieving and maintaining its competitive advantage" (Đorđević-Boljanović, 2009, p. 21).

So, it is not enough for the companies just to achieve the current competitive advantage, but it is al-so necessary to keep that position in the future. This task is implemented by permanent and continuous education of the employees and managers of the organization. All these activities should be carried out through a system of formal and informal education and training through a structured, systematic ap-proach. Therefore, a fundamental element of sustainable competitive advantage of modern organiza-tions is precisely the knowledge that the organization or its managers and employees have, how effec-tively they use this knowledge, and how quickly an organization acquires and uses new knowledge. Modern organization is just one organization that learns, remembers and acts in the era of knowledge based on the available information and knowledge.

The transformation of the organizations from industrial society to a knowledge society, which oc-curred in the 80 's and 90's of the 20th century, was not possible without the action of a wide range of management concepts. These concepts are: "The learning organization, intellectual capital, core com-petence, TQM (Total Quality Management), Business Process Reengineering, Knowledge Management and others' (ĐorđevićBoljanović, 2009, p. 21).

Educational strategies based on the concept of lifelong learning encompass all educational paths (Damjanović, 2006, p. 58-59):

Formal school education which is carried out in the school and is open to all ages;

Informal extracurricular education is the education of a more flexible organization that can be real-ized in the context of different teaching methods, and is intended for adults and children;

Self-education is a form of education that self-organized person who learns with and without in-structions, and occurs as a function of supplement school learning, but also out of it and take it and young adults;

Informal education is spontaneous and unplanned learning through a variety of life situations.

All these educational pathways mostly talk about the development of the awareness and practice to adequately meet the educational needs of people. The strategy not only recognizes the educational needs of ordinary workers (employees), but also a wide range of educational needs of executives and officers (managers), which covers the entire social system of education needs.

The basis of the design of a strategy for functional training and development is as follows (Brekić, 1994, p. 193):

- The system of training and knowledge innovation is set to be in line with the role and influence of the executives on the efficiency and the development of modern enterprise organization in the changed economic conditions;

- The program should provide the knowledge to the manager and information necessary to per-form this profession in a modern way, and enable them to constantly innovate existing knowledge;

- Program structure is flexible, which will be updated on the basis of research results typology of managerial functions and skills necessary to perform them in practice.

\section{How to implement changes in educational institutions?}

Authors who work in the field of change management have come to accept that just about the only thing that seems to be constant in this day and age is change.

However, organizations and companies sometimes don't spend enough time thinking about how to manage change. Here are some things to have in mind before undertaking, planning and implementing any 
significant change within a school environment:

- Management of the perception

Many people see change as something that just happens, something that's "done to them" without their consent and outside their control.

Sometimes this is true, but for most undertakings within a school environment teachers and admin-istrators have some autonomy as to how (or even if) change is effected. The more opportunity and en-couragement people are given to have some input, the more control they will feel and the more "buy in" will occur with the staff. Research shows pretty clearly that a greater sense of ownership is more likely to lead to successful change implementation within an organization.

- Ensuring to make the change a part of the educational institution's culture

Just as some people are more comfortable with change than others, some organizations are more comfortable with change.

For educational institutions where change is anathema, starting with small but visible changes that make a positive difference, is the key. As these small changes accumulate, staff members become more open to trying out new things. If something that's undertaken doesn't work, or has unintended consequences don't hide it, failure is also a learning experience.

Dealing effectively with setbacks is critical if change is going to be an accepted part of a school's culture. But jumping in with both feet, trying to "impose" significant change on a staff before its members are comfortable with new ideas and processes will doom the project before it's even started.

\section{- Appreciation of the skeptics and criticism}

When someone is questioning a proposed change the first reaction can be to get frustrated or even angry.

What is important to keep in mind is that though it is always good to have skeptics in the mix, they ask the tough questions. If someone asks a reasonable question for which we can't provide a reasonable answer then we need to rethink something that's being proposed. It is great to be optimistic about new initiatives, but the skeptics and critics are the ones that keep us grounded in reality.

- Acceptance of the history of change within the organization

Before moving forward with new ideas it is good to always look to the past. What was the last sig-nificant initiative?

When was it undertaken?

What impacts has it had?

Organizations that undergo change too often (or perpetually) tend to become jaded about new ideas, and organizations that have had negative experiences with change will be much more reticent to try new things. There are no hard and fast rules, but as with many things in life, looking to the past can provide vital information regarding how things may (or may not) work moving forward.

\section{- Awareness of preconceived notions}

There are many stakeholders in education - students of course, but also administrators, teachers, and parents.

All members of the latter three groups have been to school and most of them have some precon-ceived notions as to what school should be about. After all, the structures of school (both physical and metaphorical) have changed little over the past 200 years.

However, maintaining this status quo much longer is looking increasingly difficult, not to mention counterproductive. Change leaders must consider and respect individual notions of what school should look like, while at the same time convincing people that what they're proposing will be better. Not all preconceived ideas can be dispelled, after all, there are people that would rather not let common sense and reason get in the way of their opinion. But being aware of people's preconceptions (and yes, prej-udices) can help as we formulate strategies and frameworks for implementing something new, and hopefully better.

\section{Digital age teaching - development prospects}

For facilitating the process of change in schools, we have found it useful to move through each level and consider influences that may be affecting the school and how I can address those influences. 
Digital age learners must be able to connect with learning resources, information, peers and experts to effectively learn in the digital age. Providing simple tools that enable these connections is important for learning organizations.

Nowadays, under the pressure of digitalization and use of technology in the learning processes there are many creative and dedicated educators who are providing innovative, digital-age learning opportunities for their students. The following table summarizes key elements of these approaches, how they differ from traditional instructional models, and the types of teaching and learning practices (Fig.1).

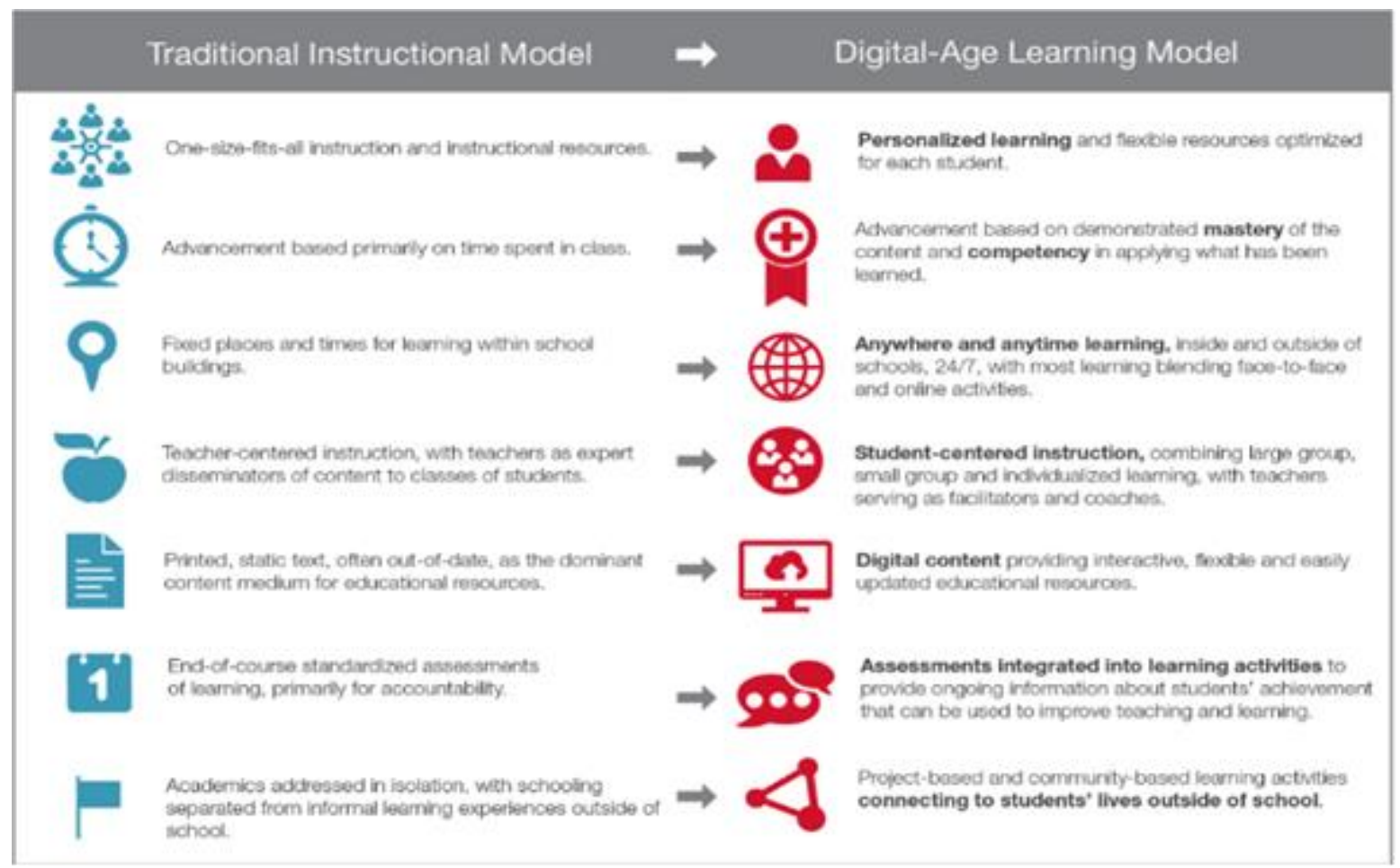

Fig. 1. Key elements of digital - age learning model (Kleiman, 2016).

Some of the elements of digital-age learning reflect approaches that many teachers incorporated long before the advent of the Internet. Recommendations for personalized learning, competency-based advancement, student-centered learning, portfolio assessments, and project-based learning go back many decades and can be found in the writings of many scholars of education. Modern technologies can make these approaches more practical to implement widely and more powerful in impacting stu-dents' learning. Other elements of digital learning, as access to anywhere and anytime online learning and to the wealth of interactive digital learning resources are only possible through the power of the Internet. All of these elements must be brought together in order to provide true digital-age learning experiences for all students.

The transition to digital-age teaching and learning involves changing the culture of teaching and learning. Teachers are no longer the keepers and conveyers of information, but rather the designers of learning experiences that enable students to productively engage with rich resources and learning ac-tivities. Teachers also become analysts of students' learning, using both their direct knowledge of each student and the data that can now be collected and instantly reported online, in order to craft learning experiences that engage students and provide appropriate levels of challenge for each one. They help students become independent learners who can make effective use of anytime, anywhere learning op-portunities and engage productively in individual and collaborative projects. They can also harness the power of social networking to enhance learning and to help their students learn how to use it appropri-ately.

While formal quality assurance regimes are increasingly focused on the student experience, they have not made student engagement the key driver for quality. Nor do such regimes look at whether the program is innovative, flexible, making great use of technology for learning analytics and assessment and is engaging students with potential applications of that learning.

Indeed, the model of pedagogy prized by many quality assurance regimes is particular and specific and derived from face-to-face as the "gold standard", despite the varied quality and experience of face-to-face instruction. 
A great many quality assurance regimes do not look seriously and critically at learning impacts over time impact on career, impact on lifelong learning, and impact on community resulting from that learning - nor do they look in depth at student engagement and faculty satisfaction as drivers of quality. We still have a lot to do to bring our thinking about quality "up-to-date".

Digital technologies provide increasingly powerful tools and offer a variety of educational oppor-tunities that can improve teaching and learning. These principles offer crucial guidelines for adminis-trators, teachers, and technology staff in planning and managing the role of technology in independent schools.

\section{Principles of good practice: Leadership}

- The educational institution regularly evaluates its use of technology to support its mission, goals, and program;

- The leadership of the educational institution incorporates technology considerations into strategic planning and creates a sustainable financial model for its technology commitments;

- The educational institution's technology leader is a member of one of the leadership teams and has the training, authority, and support needed to influence key areas of policy development, decision making, budget, and management;

- The educational institution ensures that faculty, staff, and students have equitable access to the technologies they need to support the school's mission, goals, and program;

- The educational institution recognizes that any innovative teaching and learning exploration, in-cluding technology innovation, often requires significant support for faculty professional development and flexibility in schedule and program;

- Educational institution leadership establishes school-wide expectations and provides ongoing professional development regarding the integration of educational technology into the school curricu-lum;

- Educational institution leadership, academic leadership, and technology leadership work together to ensure the development, implementation, and evaluation of technology at the school;

- Educational institution leadership regularly investigates and evaluates how emerging technologies impact, or may impact, the sustainability of their academic and financial models.

\section{Teaching and Learning}

- Educators research, evaluate, and employ technology as befits their mission and philosophy to provide differentiated personalized instruction and to achieve curricular goals;

- Educators understand that content is readily available with technology and design environments to transform the relationship between teacher and learner, engaging students in higher-order thinking skills, creation of content, and critical thinking;

- Educators embrace technologies that promote a culture of participatory and collaborative ap-proaches to learning (such as inquiry-based, student-centered, flipped classroom, and project and prob-lem-based learning);

- Educators model and empower learners to effectively practice media and information literacies inside and outside the classroom as content creators and consumers;

- Educators promote networking opportunities for their students and teachers to collaborate locally and globally;

- Educators evaluate opportunities to leverage online and/or hybrid learning environments and im-plement them when they enhance student learning;

- Educators explore technology-enriched and adaptive formative assessments for sophisticated and customized skills evaluation that reveal growth over time and that inspire intrinsic motivation to im-prove learning.

\section{Professional growth and learning}

- The educational institution recognizes a critical factor in technology integration is the teacher's sustained professional growth by creating a culture of continuous growth and adequate support for in-novation and learning; 
- Educational institution leadership encourages educators to seek out opportunities to build learning networks and to explore and evaluate digital tools;

- The educational institution includes technology integration as an essential component of its pro-fessional development, provides the necessary time and resources for it, and ensures that educators acquire and demonstrate essential technology skills and proficiencies;

- Teachers' use of technology for teaching and learning is included in the school's teacher evalua-tion process, as appropriate for the school's mission and philosophy.

\section{Infrastructure and administrative operations}

- The educational institution uses technology to improve the efficiency and effectiveness of ad-ministrative operations;

- The educational institution provides adequate staffing and infrastructure appropriate for its size and operation;

- The educational institution maintains, protects, reviews, and enhances its technological resources (data, network, software, and hardware) each year;

- The educational institution provides timely support for digital resources and the people who use them;

- The educational institution establishes renewal plans, replacement cycles, and disposal plans for technology equipment.

\section{Digital ethics}

- The educational institution engages in ethical business practices in its digital technology initia-tives, including considering the public purpose opportunities of online course offerings that extend beyond its own school community;

- The educational institution operates under a clear set of practices/guidelines for maintaining pri-vacy, confidentiality, and security in its use of digital technology;

- The educational institution develops a responsible-use policy that is framed in the positive, flexi-ble enough to accommodate changes in technology, and frequently reviewed;

- Educators teach, model, and expect safe, healthy, ethical, legal, and responsible use of digital re-sources and social media by students and parents;

- The educational institution develops a policy regarding faculty and student interactions on social media sites;

- The educational institution provides up-to-date information on fair use, copyright, and Creative Commons information and requires compliance by faculty, staff, and students;

- The educational institution establishes a curriculum-based digital citizenship/digital responsibility program that includes ongoing discussions of online behavior, cyberbullying, and respectful and legal use of online tools;

- The educational institution stays current on issues, events, and concerns related to online behav-ior and digital citizenship and informs faculty, students, and parents when appropriate.

\section{CONCLUSION}

Over the past 20 years the use of digital assets and technology has accelerated and it continues to grow exponentially.

Digital technology is becoming increasingly present in everyday life: from schooling and education, to political engagement and even financial and health management (Grand-Clement, 2017, p. 1).

Developments in digital technology and the speed at which they emerge, drive innovation and new applications that touch our lives in different and often profound ways. While there are numerous opportunities and aspirations associated with digitalization, there is also a crucial need to understand and mitigate the challenges it presents to society.

The digital world is increasingly penetrating the education and skills domain, with technology gradually being used to deliver education, knowledge and skills in new and innovative ways. This penetration is coupled with 
future changes to the mode and pattern of work, which are themselves af-fected by the current climate of economic uncertainty, as well as by political shifts. Given the increased use of fast- changing digital technologies in the workplace, new skills needs have emerged. The use of these technologies has contributed to transforming learning and skills development into a lifelong process. Indeed, people now have to continue to develop and refresh their skills and knowledge continuously in order to keep the pace with the constant innovations and new developments in the digital world. It is estimated that technology skills have to be updated every three years in order to have continued relevance. This applies to the workforce in general, where emphasis is placed not so much on knowing the information, but rather on how to find it, and the ability to assess its quality and reliability (Ovcharova, 2007a-b).

The educational institutions are not immune to the ongoing changes in the everyday life. Educa-tional institutions shall provide the business sector with a worker who is skilled, knowledgeable and ready for new knowledge and skills. Under the pressure of digital age and the shift of competences of the workers, educational institutions shall create a worker that will understand the importance of: Knowledge management (validation of information, quality assurance of information); Change man-agement; Agile management (responsiveness, iterative process); Self-learning and lifelong learning; Discerning the limits and barriers of technology (e.g. knowing when technology is helpful and when it is not); Creation of ambient for learning for tomorrow - not for yesterday or today; Aware of the pro-cesses of planning, projecting, assessment; Projection of the future; Creation of cultural ambient; Sup-port of lifelong learning culture; Logical thinking the world as a system of relations; Ability to create and acknowledge information and knowledge; Ability to communicate; Ability to realize plans; Life harmony; Acceptance of differences; Transformation of the slow educational system into flexible composition of changes (Bogdanov, 2016a-b; Bogdanov, 2019).

\section{REFERENCE LIST}

Alibabić, Š. (2010). Obrazovanje i učenje odraslih-jezgro menadžmenta promene.

Obrazovanje odraslih, 10(1): 103-118.

Brekić, J. (1994). Inovativni menadžment. Zagreb: NP Alinea.

Cvetković, N. Kotlica, S. (2007). Nova ekonomija u svetu koji se menja. Beograd: Meg- atrend univerzitet.

Damjanović, P. (2006). Strateško planiranje u obrazovanju. Banja Luka: Zavod za udžbenike i nastavna sredstva Istočno Sarajevo.

Djordjević-Boljanović, J. (2009). Menadžment znanja. Beograd: Datastatus.

Dimitrovski, R. (2012). Change Management, Institute of Knowledge Management, Skopje, Macedonia, ISBN 978-9989-2915-6-2.

European Commission. (2018). Education and Training MONITOR 2018, available at https://ec.europa.eu/education/resources-and-tools/document-library/education-and-training-monitoreu-analysis-volume-1-2018_en (accessed on 05.05.2019).

Grand-Clement, S. (2017). Digital learning - Education and skills in the digital age. Cam-bridge, UK.

Hussain, S.T.et al, (2018a), Kurt Lewin's change model: A critical review of the role of leader-ship and employee involvement in organizational change, Journal of Innovation and Knowledge, pp. 123 - 127, DOI https://doi.org/10.1016/j.jik.2016.07.002.

Kleiman, G. (2016). Digital Age Learning and Teaching, NC State University College of Ed-ucation, available at http://www.hunt-institute.org/resources/2016/02/digital-age-teaching-and-learning/ (accessed on 07.05.2019).

Ovcharova, Sn. (2007a). Knowledge management in some Bulgarian organizations. 6th International congress "Knowledge Economy \& Management", 26-28 Dec.2007, Istanbul, Turkey, 2007, pp.19081915. ISSN 1308-3937.

Ovcharova, Sn. (2007b). Motivation in knowledge economy. 6th International congress "Knowledge Economy \& Management", 26-28 Dec.2007, Istanbul, Turkey, 2007, pp.1643-1651. ISSN: 1308-3937.

Bogdanov, Plamen. (2016a). Osnovi na ekspeditsionnite sposobnosti. // Voenen zhurnal, Voenna akademiya "Georgi Stoykov Rakovski“, Sofiya, br. 1, 2016, str. 68-74, ISSN 0861-7392. (Богданов, Пламен. 
Основи на експедиционните способности. // Военен журнал, Военна академия „Георги Стойков Раковски“, София, бр. 1, 2016, стр. 68-74, ISSN 0861-7392).

Bogdanov, Plamen. (2016b). Air power - Today and tomorrow. // Tenth international scientific conference: The power of knowledge 7-9.10.2016, Agia Triada, Greece, IKM - Skopje, 14, 2016, N 1, pp. 331-336, ISSN 1857-92.

Bogdanov, Plamen. (2019). Perspectives and development of the the Bulgarian military - educational system. // Security of Central and Eastern Europe Countries 1st International Scientific Conference of Military Academies/Universities, WROCLAW, 20-22.03.2019, organized by General Tadeusz Kosciuszko Military University of Land Forces, Scientific Journal of the Military University of Land Forces, volume 50, no. 1 (187), 2019, p. 73-89, ISSN 2544-7122. 